\title{
UNILATERAL ELECTRO-CONVULSIVE THERAPY
}

\author{
S. M. Cannicott, M.C., M.A., M.B., B.Ch., D.P.M. \\ Assistant Psychiatrist, Mendip Hospital, Wells, Somerset \\ Late Senior Registrar, Holloway Sanatorium
}

SINCE its inception in 1938 by Cerletti and Bini, bilateral ECT has proved the most widely used and successful of modern psychiatric treatments, but at a price. Many patients, especially psychoneurotics and arteriosclerotics, complain of memory difficulties associated with recent events; many show post-convulsive confusional states; and a minority complain of a feeling of blottingout-' the agonising experience of the shattered self' (Schildge, I947; Stengel, I95 I; and Taylor and Pacella, I948), whilst Anderson (195 I and 1953) quotes examples of poets who ceased creative work following electro-convulsive therapy, and professors and students who forgot large parts of their knowledge.

These symptoms have been investigated quite thoroughly in the past and have caused a certain amount of controversy. It was often taught that they were a hysterical reaction to the treatment and would soon pass away; yet many psychiatrists have had experience of patients whose memory disturbances have been very severe and lasted for some considerable time. Gutman and MayerGross (1943) said the amnesic period lasted for almost one hour after treatment and, if a series of shocks were given, several hours. This memory disturbance was quite separate from the immediate post-shock amnesia. Bersot (1943) found in some cases a disorientation to time and place, and an amnesia, lasting up to ten hours.

The considerable work on this has recently been reviewed by Brengelmann (1959) in a paper in which the effect of repeated electro-shocks on depressives was considered. He states 'The more reliable experiments appear to favour the conclusion that learning function is impaired after the third shock and especially about the fifth ... whether learning capacity is at the same time also severely handicapped, cannot be decided on the clinical evidence, but the simple amnesia, disorientation and 'Korsakow-like' states reported suggested impairment of immediate memory. As memory has great importance for learning, the evidence strongly suggests impairment of learning capacity'.

Ritchie Russell (1959) says 'Intelligence seems to depend on the capacity to associate a vast number of memories with each other and one memory seems to be built on previous memories '. Both these workers would suggest that the impairment of memory involves a good deal more than a simple forgetting of recent events: 'Intelligence seems to depend on the capacity to associate a vast number of memories with each other and that if this memory disturbance is at all severe the intelligence will be, temporarily at least, affected'. 'The work of Cronholm and Molander (1957), applying a battery of tests to patients before and after ECT, tends to confirm these views and Stone (1946) suggested a general impairment of cognitive functions after ECT, usually of a temporary nature.

Brengelmann (1959), in reviewing the vast literature, states that with the memory impairment there is a very definite time relationship. There is seldom any interference after the third or fourth treatment, but usually by the seventh. Different apparatus and techniques and the use of anæsthetics on controlled tests have not been shown to affect these amnesic results in any way (Brengelmann, I959). The EEG changes tend to run parallel with involvement of memory (Pacella and Barrera, 1942). There is usually little gross abnormality after the first three shocks but on the fourth to fifth gross changes are seen quite often, which may last for days or even weeks (Brengelmann, 1959).

The similarity of recovery from brain injury and from ECT is very striking. Ritchie Russell (1959) lists the following signs seen on recovery from a simple concussion:

(I) Return of simple reflex activity.

(2) Return of restlessness and purposeless movements.

(3) Movements more purposeful but no speech or understanding.

(4) Restless movements and the return of a few words or phrases, often explosive.

(5) Return of uninhibited speech and action; disorientated and amnesic for current events and may confabulate about the injury. 


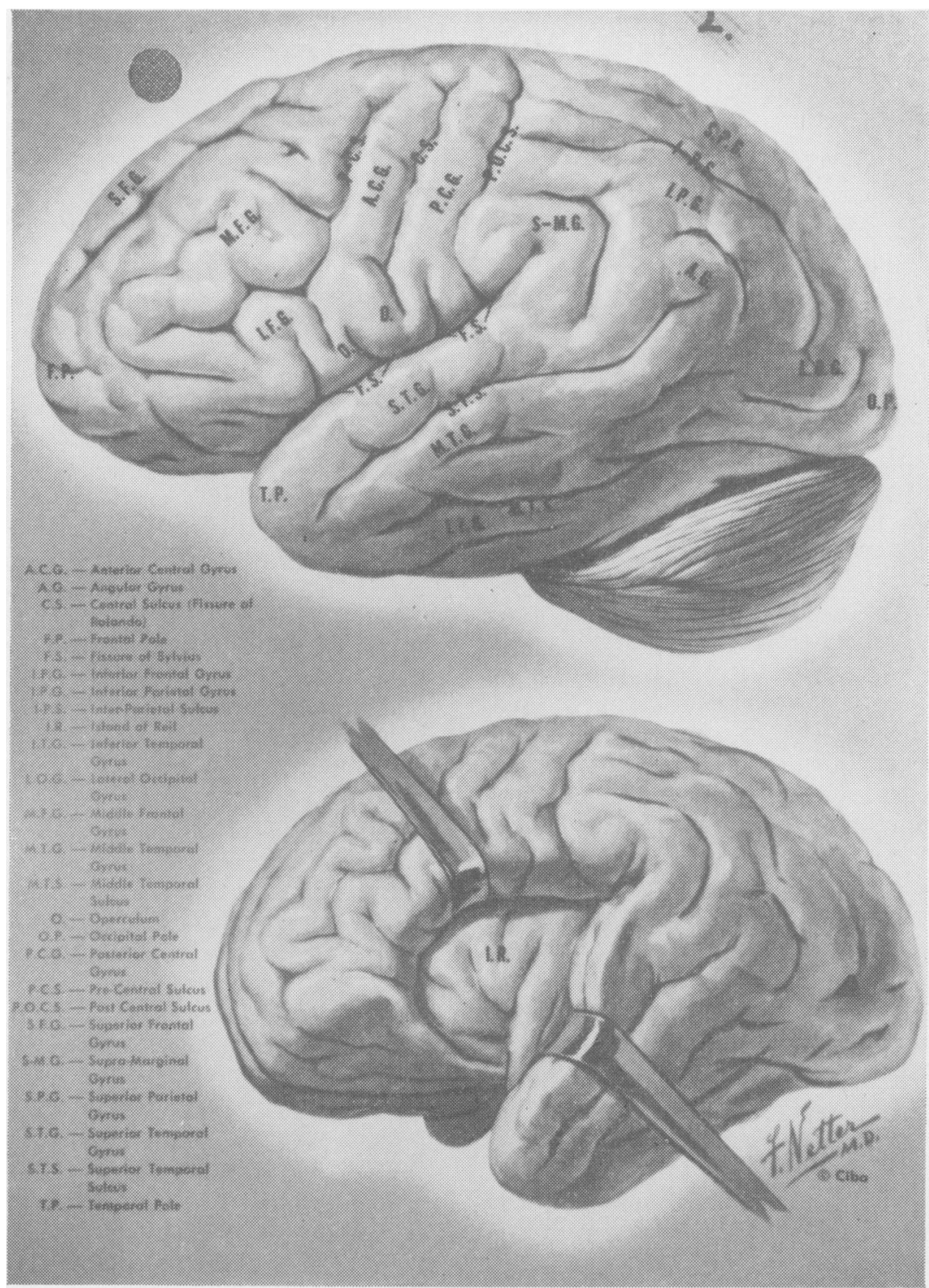

FIG. I. (Copyright, 'The CIBA Collection of Medical Illustrations', by Frank H. Netter, M.D.)

(6) Return of orientation, social decorum and behaviour.

The limits of permanent amnesia become established in general, and a capacity for rational thought only returns when this last stage is reached. Ritchie Russell goes on to point out that the faculties which are first lost in senile dementia are the same that recover last after concussion. This brief description is typical of the recovery of most patients from bilateral ECT.

The period of amnesia shows a recovery not in order of importance but in order of time. The longer memories are the first to return, and the temporary forgetting of relatively recent memories may be very marked for several hours. For a time the patient may return to his childhood similar to a state that arises in senile dementia; ECT patients often report this. "We are forced to the conclusion that as memories become older they become more strong, irrespective of their importance to the individual while recent memories are relatively liable to traumatic extinction, however important they may be ' (Ritchie Russell). 'The apparently lost memory material obeys 
the normal rules of forgetting' (Mayer-Gross, I943).

Although a good deal of testing has been done to show the disturbance of memory in ECT, there has been little to suggest its causation. The essential feature in bilateral ECT is the passing of an electric current transversely across the brain; this current passes through the dominant lobe and involves the temporal lobe and the quadrilateral memory speech area (the superior temporal convolution, the angular and supramarginal gyri, the posterior end of the third frontal convolution (Broca's area), the insula and the posterior end of the second frontal convolution) (Fig. I). A British Medical Journal editorial (1958) in discussing the anatomy and physiology of memory said 'Perhaps many of the complicated neuronal pathways which subserve the functions of learning and recall in the brain may traverse the centre of the temporal lobe'.

There is a surprising dearth of any attempt to investigate this. Psychiatrists have ranged themselves into those who approve of ECT and those who condemn it, although Kerman (1947) says ' One must be alert for memory impairment. The aim is to steer between the boundaries of mental symptoms and marked amnesia', and Gutman (1947) writes "It was tried to avoid "organic dementia " by means of short treatment'. Whilst Mather (I946) comments 'Impairment of memory is a psychological complication'.

The only paper that the writer has discovered on this subject was read to the Royal MedicoPsychological Association in Bristol in May, 1957, by Lancaster, Steinert and Frost. They suggested that if it be possible to pass the current through the non-dominant lobe and induce an epileptic fit, comparable results might be achieved without ' commotio cerebri' of the dominant lobe. They carried out a small controlled series of 43 patients and came to the conclusion that whilst there was no statistical 'significant' $(\mathrm{P}=0.05)$ difference between improvement caused by bilateral fits and the unilaterally induced fits, there was a 'significant' difference in memory disturbance. They suggested that unilateral ECT should be routinely given to patients of very superior intelligence, and especially those who have to earn their living with retained knowledge. Their work does not seem to have attracted particular attention or to have been taken up in any way, and the writer decided to make a more intensive investigation of the possibilities of unilateral ECT.

\section{Pilot Scheme}

Before carrying out a full clinical trial, it was decided to try out a pilot scheme in order to evolve a technique and to investigate the best possible methods of designing the trial (Finney, I955; Fisher, 1954). This scheme was carried out in an informal unit catering purely for minor depressive and neurotic disorders (females); it was part of a large mental hospital but situated two and a half miles away in the country, with its own separate staff and administration.

An initial attempt to use the ' $U$ ' shaped electrodes as supplied with the Ectron apparatus proved a failure as it was impossible to position them accurately, and some sub-shocks or focal fits were produced; so physiotherapy electrodes consisting of oval metal discs, diameter $40 \mathrm{~cm}$. with wooden handles, were obtained, and these proved highly successful.

The positioning of the electrodes was carried out as suggested by Lancaster, Steinert and Frost (1958) 'the lower electrode midway between the lateral angle of the orbit and the external auditory meatus and $I \frac{1}{2}$ in. above this line. The upper electrode 3 in. higher than the lower and at an angle of $70 \%$ to the line'. The application of electrodes to the patient's head is shown in Fig. 2. It was soon found that small deviations from these points did not particularly affect the type of shock. The only point of significance noted was that if the upper electrode was allowed to deviate downwards towards the occipital area, there were complaints of double vision and sickness.

Several observers standing behind a screen and only seeing the fit after the application of the shock were unable to tell whether a bilateral or unilateral fit had been given.

A total of 40 patients were treated, and 252 ECTs given. The nursing staff were soon enthusiastic about the new treatment as they reported that there was no post-ECT confusion, confabulation, automatism or falling out of bed; they found that dressing and bedmaking afterwards were very much easier, and it was possible to reduce the number of staff looking after the patients.

The patients themselves produced some interesting reports, which are given in Appendix I. They were all asked whether they had any memory disturbance following the treatment, but were not told that they had been given any different treatment from the usual. A typical quotation was ' This time there seems to be no lapse of memory. Last time I could not remember stupid things like people's names, details like if I had written a letter. When I came back before, I had to go to bed with a bad headache; this time I just got up and carried on normally'.

In order to have some estimate of the efficacy of this treatment, it was decided to analyse figures of ECT for a similar period of the year before in 


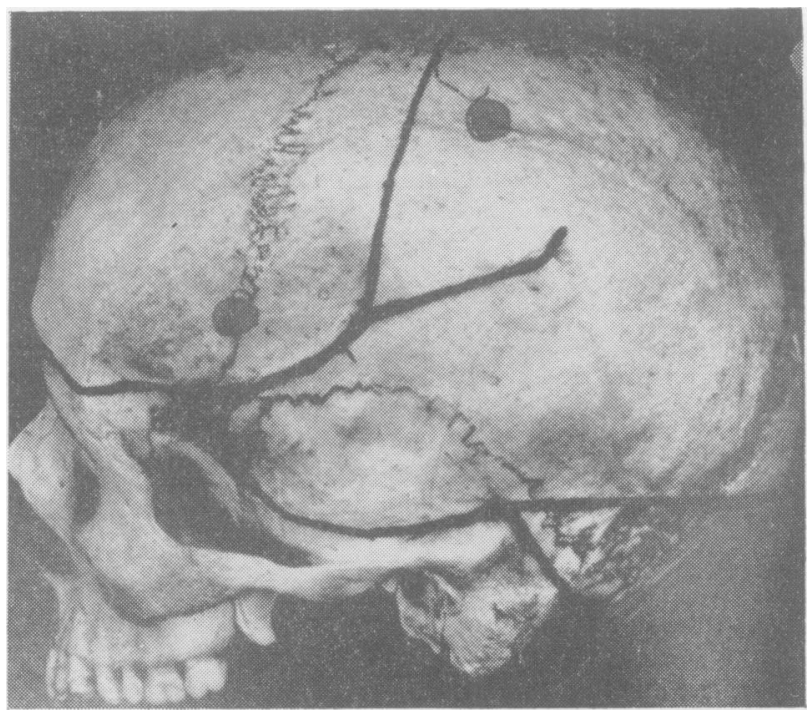

FIG. 2.

the same unit. Although the weakness and dangers of this method of retrospective ' control' are obvious, it was felt that as this was only a pilot scheme it would perhaps give some clue for future investigations.

The comparison of bilateral and unilaieral treatments are given in Tables $I$ and 2. From these it would appear that whilst there is no ' significant' $(\mathrm{P}=0.05)$ difference in response to the treatments, i.e. recovery, relieved, etc., there was a quite 'significant' reduction in confusion and headaches between the two.

The most interesting case was that of a middleaged patient who in 1954 was treated in the main hospital for endogenous depression with eight bilateral ECTs, and recovered. This time she was treated in the unit with eight unilateral ECTs and made an equally rapid recovery.

The distribution of unilateral and bilateral $\mathrm{EC}^{\prime} \mathrm{T}$ is given in Figs. 3 and 4 , Table 3 .

The pilot scheme had committed numerous statistical sins (Bradford Hill, 1955; Finney, I955).

I. The method of retrospective control is extremely suspect at the best of times (Atkins, I958), although in this particular case there was only a one-year interval.

2. There was no sampling in the selection of the cases and an unconscious bias towards minor cases that might respond to unilateral ECT was obviously quite possible and is suggested in the skewing of the distribution in Figs. 3 and 4.

3. The criteria for response, such as relieved, recovered, unchanged, worse, etc., might well have shifted in favour of unilateral ECT.
TABLE I

Pilot Scheme

ECT Results Eight Months After Treatment

\begin{tabular}{|c|c|c|c|c|}
\hline & \multicolumn{2}{|c|}{$\begin{array}{c}\text { Bilateral } \\
\text { (July-Oct. I 957) }\end{array}$} & \multicolumn{2}{|c|}{$\begin{array}{c}\text { Unilateral } \\
\text { (July-Oct. I958) }\end{array}$} \\
\hline & No. & $(\%)$ & No. & $(\%)$ \\
\hline $\begin{array}{lc}\text { Recovered } & \ldots \\
\text { Relieved .. } & \ldots \\
\text { Not recovered } & \text { on } \\
\text { discharge } & \ldots \\
\text { Still in hospital } & \ldots \\
\text { Readmission } & \ldots \\
\text { Admitted to other } \\
\text { Hospitals }\end{array}$ & $\begin{array}{l}4 \\
4^{*} \\
4\end{array}$ & $\begin{array}{r}(21.5) \\
(54.9) \\
(7.8) \\
(7.8)\end{array}$ & $\begin{array}{l}4 \\
2 \\
3 \\
\text { I }\end{array}$ & $\begin{array}{r}(30) \\
(45) \\
(10) \\
(5) \\
(7 \cdot 5) \\
(2.5)\end{array}$ \\
\hline Total cases & $5^{I}$ & & 40 & \\
\hline
\end{tabular}

TABLE 2

Pilot Scheme

Symptoms Immadiately Post-ECT

(As Recorded IN WARd BoOK)

\begin{tabular}{|c|c|c|c|c|}
\hline & \multicolumn{2}{|c|}{$\begin{array}{c}\text { Bilateral } \\
\left(\text { No. EC'Ts } 36_{5}\right)\end{array}$} & \multicolumn{2}{|c|}{$\begin{array}{c}\text { Unilateral } \\
\text { (No. ECTs 252) }\end{array}$} \\
\hline & No. & $(\%)$ & No. & $(\%)$ \\
\hline Headache & 75 & $(20.5)$ & I I & (4.3) \\
\hline Confusion & I I & (3) & 2* & $(0.7)$ \\
\hline Vomiting. & 4 & (I) & 4 & (1.5) \\
\hline c/o Amnesia & 2 & $(0.5)$ & & $(-)$ \\
\hline ," Feeling unwel & I 4 & $(3.8)$ & 5 & (1.9) \\
\hline , Double vision & I & $(0.25)$ & - & $(-)$ \\
\hline ", Giddiness & 5 & (1.3) & 一 & $(-)$ \\
\hline
\end{tabular}

*Same patient: elderly, hypertensive, arteriosclerotic. 
T:IBLE: 3

PuLOT SCHEME

\begin{tabular}{|c|c|c|c|c|c|c|c|c|c|}
\hline & & ('l'otal & V(1. of ${ }^{B i}$ & $\begin{array}{l}\text { cral } \\
\text { eatments }\end{array}$ & $3^{6} 55$ & ('l'ot: & Vo. of & $\begin{array}{l}\text { teral } \\
\text { atments }\end{array}$ & $2,52)$ \\
\hline & & Mean & Mode & Range & S.I). & Mean & Mode & Range & S.I). \\
\hline$r$ of treatments & $\ldots$ & 7.2 & 7 & I I I & 5 & 6.3 & 2 & $2-21$ & 5.5 \\
\hline f paticnts $\quad .$. & . & +5 & - & $22-67$ & 13.7 & +5 & $\cdots$ & $2+-7 t$ & 13.6 \\
\hline Number of days in hospital. & . & 73.8 & $\cdots$ & +328 & (6i). 2 & 83 & - & 9. 337 & 83 \\
\hline
\end{tabular}

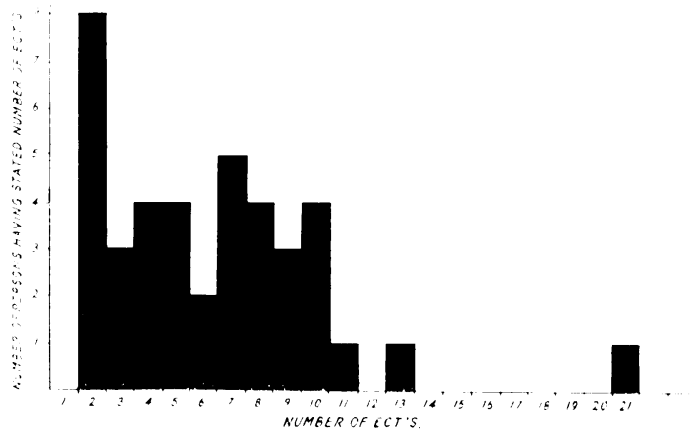

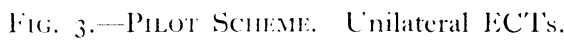

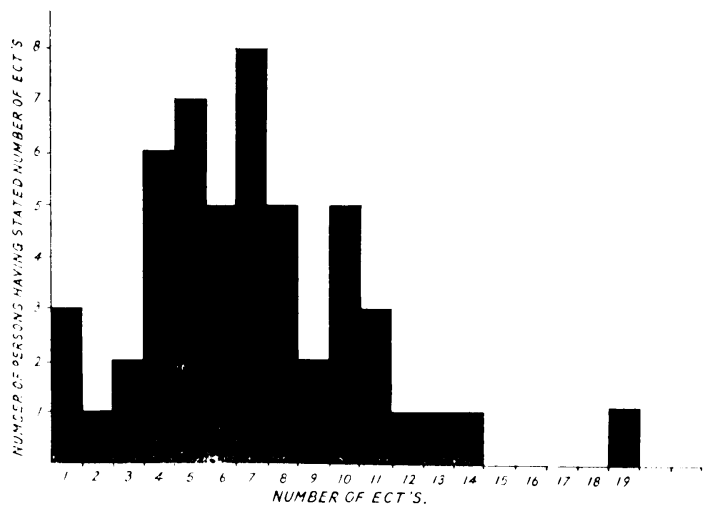

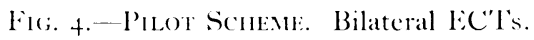

4. No attempt was made to deal with contaminants (Atkins, 1958) such as the use of moodclevating drugs, insulin and additional psychotherapy.

It was therefore decided to carry out a full clinical trial.

\section{Protocol of Clinical Trial}

'This was to be carried out on the classical pattern with proper control, sampling, and doubleblind assessment (Fisher, 1954; Finney, I955).

'liwo questions were to be asked: (1) Is unilateral EC'T as effective as bilateral in treating cases of depression? (2) Is there a reduction in post-EC'I confusion and complaints of memory impairment in the unilateral cases compared with the bilateral cases?

\section{Control}

Bilateral EC'I as a well-established treatment was considered an adequate control.

\section{Sampling}

Patients to be allotted to milateral or hilateral treatments entirely on random sampling taken from sample tables (Bradford Mill, 1955).
3. ('riteria for the Selection of Patients to be Included in the Trial

This was probably the biggest problem of all. Controversy still rages over the difference between so-called reactive or neurotic depression, and endogenous depression; and since the famous paper of Lewis (1934) it has by no means been settled.

The investigator considered firstly that only depressions be included in the trial, and that any emergency EC'I' for schizophrenia or toxic confusional states should be excluded.

'The point of view of the investigator is probably summed-up best in an anonymous article from a Geigy brochure: "The attempt to set up generally valid and strict classifications of depressive states will probably always fail. Endogenous depression, endogenous reactive depression and organic depression are inseparably related to one another. Each reacts on the other and the interactions are so complicated that a sharp limitation between them is often almost impossible'; and Kraines (1957) sums it up in a very similar way: 'Primarily it is a resultant of physiologic as well as psychologic forms; once established in either field it becomes a reciprocally acting force'. 'The selection of 
patients for inclusion in the trial therefore reduced itself to those with severe enough depression to warrant $\mathrm{EC}^{\prime} \mathrm{I}$ and those whose mild depression did not require it.

\section{Assessment}

'This was to be by the double-blind method. Patients were not informed which treatment they were having. A colleague kindly agreed to assess patients on the basis of recovered, relieved or unchanged, either when they were discharged, or after they had had up to, but no more than, ten EC'Ts. The colleague, naturally enough, was not informed which treatment the patient had received.

In order to assess the progress of patients treatment by treatment, a special chart was prepared (see Appendix II) listing the typical symptoms found in depressive illnesses. Before the first treatment the symptoms complained of by the patient were marked. Then the day following each treatment the patients were seen by the same colleague and a score was made of two points for any improvement that had occurred, one point for any symptom that was unchanged and no points if any particular symptom was worse. This assessment of change in symptomatology was obviously both objective on the investigator's part and subjective as reported by the patients. 'These scores could then be totalled up and the mean clinical values (Atkins, 1958; and Walpole, 1949) calculated. On the termination of the trial, the mean of the mean clinical values for the treatments could be calculated and then plotted.

\section{Treatments}

These were to take place thrice weekly and all patients would receive Pentothal 5 c.c. of $5 \%$ solution and Scoline 0.5 c.c. using Ectron apparatus.

\section{Contaminants}

No other treatment or medication was to bo given, except that of routine night sedatives and attendance at the Occupational Therapy Department.

7. Nurses were allotted to the recovery room in order to note confusion. These nurses were not to be informed which type of treatment the patient had received.

8 . As in the pilot scheme, although patients were not told which treatment they had received, they were asked if they had any comments on how it had affected them, other than dealing with the purely depressive aspects of the illness.

\section{Clinical Trial}

'The trial was carried out in the main hospital in a female admission ward taking all types of patients. It was terminated fortuitously due to the investigator leaving the hospital for a different post.

It had been hoped to apply simple cognitive tests like the Raven's Matrices to the unilateral and bilateral patients generally but this proved impossible due to lack of time by both staff and patients. There were no facilities to carry out EEG studies routinely. A mistake took place in the random sampling. Random sample tables were kept by the Sister of the ward, and it was her responsibility to allot patients to bilateral or unilateral treatments. It will be noted in Table 4 that 20 patients received bilateral and 30 unilateral. This discrepancy is not accounted for by the fact that two patients were changed from bilateral to unilateral because of complaints of amnesia and their resultant intention to stop treatment altogether. It is quite apparent that too many patients were allotted to the unilateral treatment because of a mistake in using the tables. This can only be explained by the fact that the Sister went on sick leave and a new Sister took over the ward and became confused in dealing with these tables. This mistake in sampling was not discovered until the trial was terminated and therefore undoubtedly reduced the rigorous standard attempted.

As in the pilot scheme, patients were again asked whether the treatment affected them in any way, except for improving their depression; once morc there were no spontaneous complaints of amnesia amongst the unilateral patients, although on questioning two did complain of considerable amnesia. These two patients were those who also suffered post-ECT confusion.

Thirty patients were treated with 209 unilateral ECTs, and 20 patients received a total of 133 bilateral ECTs. The results are shown in Table 4. With reference to Appendix II (applying $\%^{\mathbf{2}}=$ 0.9I) no 'significant' difference $(P=0.05)$ was found in response to treatment. However, the difference in confusion shown in Table 4 is highly 'significant'. This difference in confusion is even more striking when it is mentioned that seven patients receiving only unilateral treatment experienced confusion with their first treatment; this was not found in the bilaterals.

Distribution pattern of treatments (Figs. 5 and 6) shows a negative skew in the case of unilateral treatments, which is quite the reverse of the distribution pattern seen in the pilot scheme. 'This is probably explained by the fact that in the main hospital more serious depressions were treated, and it is the clinical impression of those colleagues who have tried out this treatment that unilateral ECT requires to be given rather more frequently than the bilateral. 'This change of distribution 


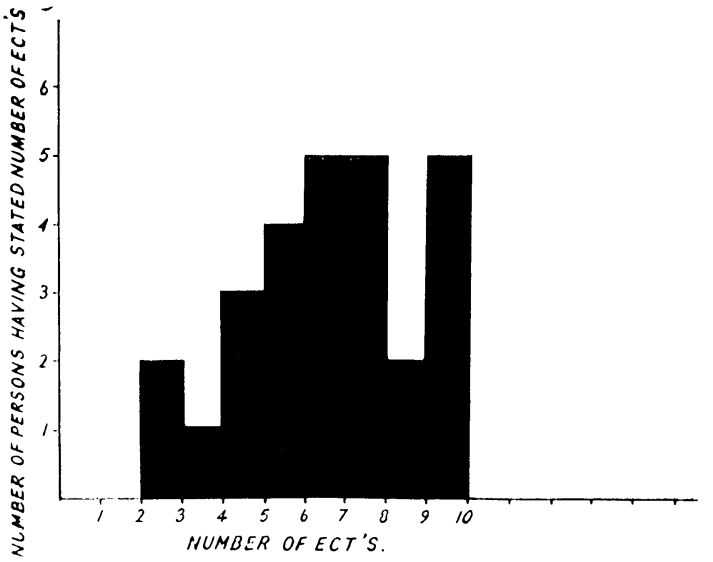

fir. 5-Cinnical 'l'rial. Unilateral EC'l's.

IABIE +

Clinicat, 'T'rial: Rrentits alter 'T'reatment

\begin{tabular}{|c|c|c|c|c|c|}
\hline \multirow{2}{*}{\multicolumn{2}{|c|}{$\ldots$}} & \multicolumn{2}{|c|}{ Bilateral } & \multicolumn{2}{|c|}{ Unilateral } \\
\hline & & No. & $\left({ }^{\prime \prime}{ }_{11}\right)$ & No. & $(" 10)$ \\
\hline $\begin{array}{l}\text { Recovered } \\
\text { Relieved . } \\
\text { Inchanged }\end{array}$ & $\begin{array}{l}\cdots \\
\cdots \\
\cdots\end{array}$ & $\begin{array}{r}1+ \\
+ \\
2\end{array}$ & $\begin{array}{l}(70) \\
(20) \\
(10)\end{array}$ & $\begin{array}{r}17 \\
10 \\
3\end{array}$ & $\begin{array}{l}(57) \\
(34) \\
(10)\end{array}$ \\
\hline 'lotal cases & $\ldots$ & 20 & & 30 & \\
\hline $\begin{array}{l}\text { Post-EC'l } \\
\text { sion, incide }\end{array}$ & & 100 & $(75)$ & 32 & $(15)$ \\
\hline 'l'otal treatme & s. . & I 33 & & 200 & \\
\hline
\end{tabular}

may also be explained by the fact that in the pilot scheme the investigator may have been biased in favour of unilateral and therefore did not give the more serious depressions this treatment. 'The response in treatment suggests that bilateral E('I' works a little quicker than unilateral; this is certainly the clinical impression of the investigator.

\section{Out-Patients}

'I 'he investigator was responsible for a separate series of out-patients who were receiving standard hilateral EC'l'. Eighty-seven patients were under treatment and 13 of these complained of such severe post-E('T amnesia that they wished to corminate their treatments. 'These were given unilateral EC'I' and no longer complained of amnesia: I I recovered completely and two remained unchanged. It is interesting to note that of this particular batch one was a school teacher, one was a church organist, one was a hypertensive patient who had shown great confusion after bilateral ECT, and one was a basically insecure and anxious personality.

\section{Discussion and Conclusions}

'The results of the trial naturally raise the in-

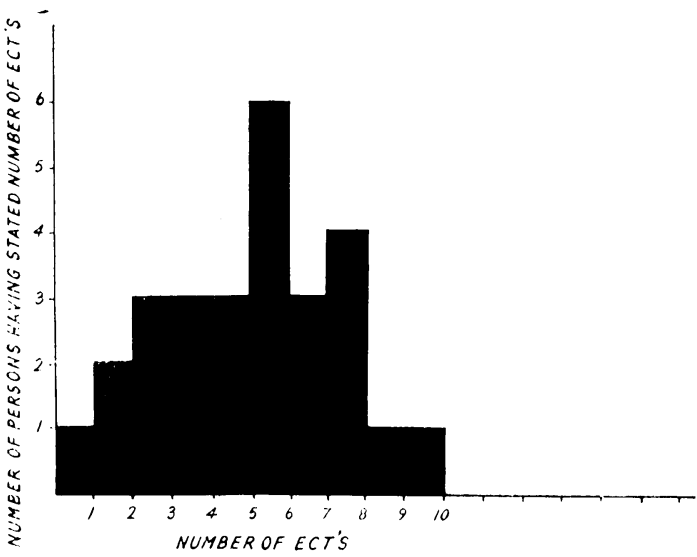

Fic;. 6.--Cinnical, Trual. Bilateral lecols.

teresting and important question of whether memory impairment is part of the benefit of $\mathrm{E}(" \mathrm{l}$. Although in 1952 \%ubin wrote "memory loss as an explanatory principle in improvements remains in doubt for the present', yet many psychiatrists have considered it an absolutely vital aspect. Milligan (1946 and I948) wrote 'I am personally certain that confusion has a definite therapeutic value', and Bennett (1943) wrote 'Memory loss is probably necessary for therapeutic effect' Myerson (1943) had written "'The mechanism of improvement and recovery seems to be to knocks out the brain and reduce the higher activities, to impair memory, and thus the newer acquisition of the mind, namely the pathological state, is forgotten'. Brengelmann (1959) writes of two lines of thought particularly supporting the value of memory impairment. One holds that electroshock impairs memory selectively, emotionally and negatively toned material being more easily forgotten, the other that psychotic symptoms, being more recent, are more readily forgotten; selective amnesia occurs it is claimed. More rigorous tests, however, showed special events in patients' life history to be affected to the same extent as other tasks which require similar processes, and forgetting appears to follow the normal rule of forgetting' (Mayer-Gross, 19+3).

Proponents of the recency theory base their arguments on the observations that the nearer the treatment the more easily are memories forgoten. Adherents of the regressive type of shock therapy and clinicians with a psycho-analytic orientation also tend to support these views. This particular investigation points quite categorically to the contrary and suggests that whatever the mechanism of improvement may be, it is certainly not that of the hattering ram. 'The investigator agrees with Garmany and Early (1948) who stated "We find that the statement that such traumatic clouding is 
therapeutically valuable to be one which fills us with something akin to horror'.

Further points that would require research would be (I) a follow-up to investigate whether the improvement produced with unilateral EC'T was as lasting as in the case of bilateral, (2) EEG studies, and (3) cognitive tests such as were used by Cronholmand Molander (I957) and manyothers.

\section{Summary}

A new technique of ECT was investigated, which attempts to reduce or abolish the usual confusion and amnesia which results from the standard method. This consisted of passing the current across the non-dominant lobe of the brain. A total of 154 depressed patients received 1,002 EC'Ts; 504 unilateral and 498 bilateral.

The study was divided into three parts: a preliminary pilot scheme, a controlled trial and a small series of out-patients.

In the pilot scheme, 40 patients received 252 unilateral treatments; retrospective comparison was then made with $5 \mathrm{I}$ patients who had received 265 bilateral treatments the year before in the same unit. No 'significant' difference $(P=0.05$ level $)$ was found in the response to treatment but a 'significant ' reduction was found in the confusion and amnesia produced. No patient complained of memory disturbance following treatment.

A controlled clinical trial was then carried out on classical lines with random sampling, bilateral EC'T as a control, and double-blind assessment. The controlled trial treated 30 patients with 209 unilateral EC'T and 20 patients with $\mathrm{I} 33$ bilateral ECT. Results were similar to those of the pilot scheme. There was no 'significant' difference in response to treatment at 0.05 level but a 'significant' difference in post-ECT confusion.

At the same time the investigator was responsible for a separate group of out-patients who were receiving bilateral ECT. Of the 87 thus being treated, ${ }_{1} 3$ complained of severe post-EC' $\mathrm{T}$ amnesia and confusion, and wished to terminate their treatment. These patients were accordingly

\section{Appendix I \\ Verbatim Reports}

All patients were asked whether they had any memory disturbance following $\mathrm{EC}^{\prime} \Gamma$. They were not told that they had had any different treatment than previously.

Mrs. D. N. F. 'Not terribly confused here but is years ago I did not know where I was or what had happened to me-all confused. Does not seem to affect me today - not so heavy, so drastic '.

Mrs. G. (An out-patient) Quoting after bilateral treatment: "Bought a lot of things a day after the treatment and one week later asked where all these things had come from ... you meet people you ought to know and cannot remember names or what connections'. After unilateral: 'Not so forgetful this time'.

Mrs. $Q$. (Out-patient): 'This time there seems to be no lapse in memory . . . last time I could not remember stupid things like people's names, details like if I had written a letter. When I came back before I had to go to bed with a sick headache . . . this time (unilateral) just came home and carried on normally'.

Mrs. $M$. This patient was switched over to bilateral treatment following which she showed appreciable postECT confusion and then complained that a greater strength was used in order to punish her.

Miss $K$. 'Did not confuse me so much as the kind I had before. With the other kind I had real complete blanks'.

Mrs. F. 'It interferes with recent events . . . feel awkward about it, people do not understand ... . all the houses seem to look different ... did not know where my things were at home'. (After bilateral.)

Miss $K$. 'Previous treatment affected recent events and current happenings ... you think you are not in control of yourself ... your system does not affect the memory so much'.

Mrs. C. About bilateral: "The main result was that I remembered nothing, which lasted nearly a day . . . my memory was not affected this time'. (Unilateral.)

Mrs. C. 'This treatment was very much more sub- dued than ten years ago; because when I used to regain consciousness I could not remember a thing; whereas here I had left my " Daily Mail" in the Waiting Room and I remembered to collect it after treatment'.

\section{Appendix II}

Name.

Cinical Assessment

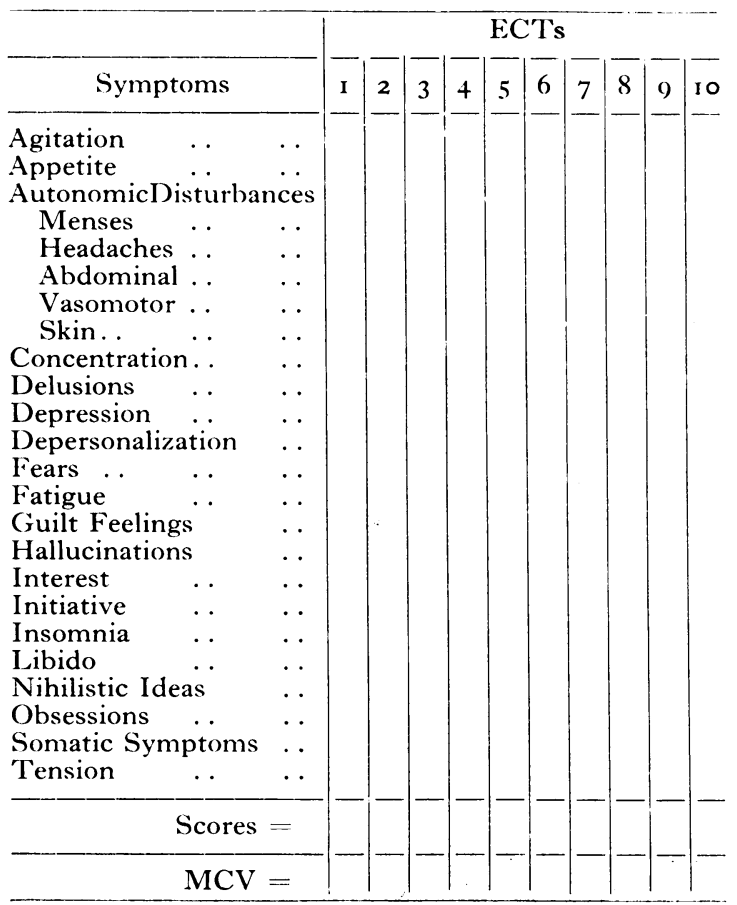


turned over to unilateral $\mathrm{EC}^{\prime} \Gamma$ and there were no further complaints of amnesia or confusion. I I of these recovered completely and two remained unchanged.

It is concluded that unilateral $\mathrm{EC} T$ is as effective as bilateral ECT in the treatment of depressions but produces a significant reduction in confusion and amnesia. It is thus a useful addition to the treatment of depressed patients, and it is suggested should be the treatment of choice for all outpatients and for those intellectual workers who must earn their living by retained knowledge.

I acknowledge with thanks the facilities provided by the Superintendent of Holloway Sanatorium and the assistance of the Staff.

\section{REFERENCES}

Andirson, E. W. A. (r95 I): Mental Disease: Physical Methods of Treatment, Medical Annual, p. r73. Bristol: John Wright.

- (r 952): Mental Disease: Physical Methods of Treatment, Ibid., p. 225. Bristol: John Wright.

- (1953): Mental Disease: Memory Changes Following ECT, Ibid., p. 234. Bristol: John Wright.

A'trins, H. J. B. (1958): 'Three Pillars of Clinical Research, Brit. med. $\mathcal{F}$., ii, I 547 .

Bennetr, A. E. (1938): Convulsive (Pentamethylenetetrazol) Shock Therapy in I)pressive Psychoses, Amer. F. med. Sci., 196, 420 .

- (1943): Curare: A Preventive of Traumatic Complications in Convulsive Shock Therapy, Amer. Y. Psychiat., 97, 1040.

Biseso'T, M. H. (1943): Auto-observation de l'Electro-choc, Ann. méd-psychol., ror, 488.

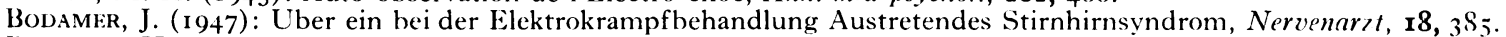

BradFord Hill, A. (1955): Principles of Medical Statistics. London: I ancet.

Brengilmann, J. C. (1959): The Effect of Repeated Electric Shocks on Learning in I)epressions. Berlin: Springer.

Cisiletti, I., and Bini, L. (1938): Un Nuovo Methodo di Shockterapia 'I,'ettroshock', Boll. Accad. metl. Roma., $64,136$.

Cronholm, B., and Molander, L. (1957): Memory Disturbances after Electro-convulsive Therapy, Acta. Psychiat. scand., 32, 280.

EutTORIAL (1958): Brit. med. $\mathcal{F}$., i, r 401 .

Finney, D. J. (1955): Experimental Design and its Statistical Basis. London: Cambridge University Press.

Fisher, R. A. (1954): The Design of Experiments, i 2th edition. Edinburgh: Oliver and Boyd.

Garmany, G., and Early, D. F. (1948): Electronarcosis (correspondence), Lancet, i, 6 I 4.

(inigy (i 959): Depression. Manchester: Geigy.

Gutman, E., and Mayer-Gross, W. (i 943): The Psychology of Pain, Lancet, i, 22.

Gutman, Y. Y. (1947): Nevropat. i Psikhiatr., r6, 50.

Kreman, E. P. (1947): The Efficacy of Electroshock Therapy in Preventing or Shortening Hospitalization, 7 . nerv. ment. Dis., ro6, I.

Kraines, S. H. (r957): Mental Depressions and their Treatment. London: Macmillan.

I.ANCASTER, N., Steinert, R., and Frost, I. (1958): Unilateral Electro-convulsive Therapy, f. ment. Sci., Io4, 22 i.

I.ewis, A. J. (1934): Melancholia: A Clinical Survey of Depressive States, Ibid., 8o, 277.

Mather, N. J. de V. (I946): Psychoneurosis Treated with Electro-convulsions (Correspondence), Iancet, ii, 6r 5.

MAYER-Gross, W. (r 943 ): Retrograde Amnesia, lhid., ii, 603.

Meyer, J. E. (r95I): Uber Schockamnesien und ihre Beziehung zum Heilverlanf der Psychosen, Arch. Psychiat. Nervenkr, 186, 254.

Milligan, W. L. (1946): Psychoneuroses Treated with Electrical Convulsions, Lancet, i, 225.

- (1948): Electronarcosis (Correspondence), Ibid., i, 537.

Myerson, A. (1943): Borderline Cases Treated by Electric Shock, Amer. F. Psychiat., roo, 355.

Pacella, B. L., and Barrera, S. E. (1942): Some Considerations of the Electroencephalogram in the 'Convulsive State' (Electrically Induced Seizures), F. nerv. ment. Dis., 96, 125.

Russell, R. W. (1959): Brain Memory Learning, ist edition, Chaps. 5, 6, 7. I condon: Oxford University Press.

Schildge, E. ( 1947): Zur Erlebnisseite der Elektrokrampfbehandlung. Kongress f. Neurol. Psycjiat. Tuebingen: Bericht.

Strngel, E. (195 I): Intensive ECT., F. ment. Sci., 97, 1 39.

Stone, C. P. (1946): Amer. Psychologist, I, 254.

TAylor, R. M., and Pacella, B. L. (I948): The Significance of Abnormal Electroencephalograms Prior to Electroconvulsive 'Therapy, $\mathcal{F}$. nerv. ment. Dis., 107, 220.

Walpolf, A. L., and Paterson, E. (I949): Synthetic (Estrogens in Mammary Cancer, Lancet, ii, 783.

Zubin, J. (1952): Abnormalities of Behaviour, Aun. rev. Psychol., 3, 26 I. 